\title{
Effect of back Massage on Lactation among Postnatal Mothers
}

\author{
Patel $\mathbf{U}^{1}$, Gedam DS ${ }^{2}$, Verma $\mathbf{M}^{3}$ \\ ${ }^{1}$ Dr. Umesh Patel, MBBS, MD, Assistant Professor, L.N. Medical College, Bhopal, India, ${ }^{2}$ Dr. D Sharad Gedam, MBBS, \\ MD, Associate Professor, L.N. Medical College, Bhopal, India, ${ }^{3}$ Mrs. Mamta Verma, Professor cum Principal, L.N. Nursing \\ College, Bhopal, M.P. India.
}

Address for Correspondence: Mrs. Mamta Verma, Professor cum Principal, L.N. Nursing College, Bhopal, M.P. India. Email: mamta.nursing@aiimsbhopal.edu.in

\begin{abstract}
Introduction: Lactation is affected by a large number of factors. Equally important as spreading the message of exclusive breast feeding is enabling mothers to sustain it adequately. Considering the ease of implementation and obvious lack of adverse effects, non pharmacologic measures are an attractive option over pharmacologic measures for improving lactation. Methods: A quasi experimental study was conducted for a period of 16 months, to assess the effectiveness of back massage on lactation among immediate postnatal mothers. A total of 220 mothers were enrolled in two groups (Group A, Experimental group-100 cases, Group B, Control group-120 cases). The effect on lactation was assessed based on various parameters, related to the baby. Results: There was significantly higher post feed weight gain, higher mean number of urinations and stools passed per day, longer duration of post feed sleep and better satisfaction in the study group compared to the control group. Conclusion: Back massage was effective in improving lactation in all parameters assessed. This can be recommended for all breastfeeding mothers, especially those facing problems with initiation and sustenance of breast feeding. Importantly, this is a simple method which can be implemented using the existing healthcare system, without straining resources.
\end{abstract}

Key words: Back massage, Lactation, Primipara, Breast Milk.

\section{Introduction}

Breast feeding is the best gift to a newborn from the mother. Human milk is the best nutrient source for term as well preterm infants for the first six months of life. It is recommended that infants should be exclusively breast fed for the first six months of life and breast feeding continued with the addition of solid foods after six months of age. Indian academy of pediatrics, American academy of pediatrics and World health organization strongly advocates this practice.

Exclusive breast feeding for initial six months is an important tool to reduce infant mortality rate in developing countries. It has been shown that breast milk decreases the rate of common infections even in preterm babies[1]. Early feeding and nutrition have been found to have a role even in the origin of type- 2 diabetes, hypertension, obesity and coronary artery disease/ischemic heart disease and other life style \& metabolic diseases. Unless a medical condition precludes it, breast feeding should be started immediately after birth.

There are numerous factors potentially associated with lactogenesis in humans. Maternal factors include mode of delivery, labour experience [2], body mass index, smoking, surgery, breast \& nippl abnormality, illness, anxiety and stress $[3,4,5]$ even fetal stress can effect negatively on lactation [6]. Behavioral factors are equally important, psychogenic induction can facilitate breastfeeding. Motivation for breast feeding, social support, nursing frequency and good breast feeding experience are other factors have positive impact on lactation [7].

Psychological stress, resulting from pain \& fatigue after labour, lack of support to mother and difficulties encountered on initiation of breast feeding causes Neuroendocrine dysregulation leading to irregularities in hypothalamuspituitary- adrenal axis function, leading to delayed onset of milk production and insufficient milk volume [8]. The National Family Health Survey-3 (NFHS3) published in 2006; only $24.5 \%$ of new mothers initiate breast feeding in $1^{\text {st }}$ hour after birth. Only $46.4 \%$ exclusively breast feed up to 6 months Data indicate India is well below the healthy people 2010 goals [9].

There is widespread need of identifying practical issues in implementing early breast feeding and sustaining it. Simple and less expensive methods applicable to vast majority of the population should be an answer. For many years China has used Acupressure to increase milk 
production [10]. Acupressure, also called shiatsu, is the application of pressure with thumb and fingertips to point on the body for therapeutic effects in form of back massage.

As acupressure is well known to provide relaxation, we hypothesized that this should help decreasing stress and anxiety of new mothers and help in stimulating lactation.

A few earlier studies have supported this. To test our hypothesis, we conducted a quasi experimental study. The aim of the study was to assess the effect of back massage on lactation indirectly via various parameters. Our goal was to find a simple, practical solution to an important child health issue, which wouldn't pose economic strain on the public health system.

\section{Material and Methods}

\section{Study Design-}

This was a quasi experimental study conducted on two groups (non equivalent) in a pre \& post test design to assess the effectiveness of back massage in lactation among immediate postnatal mothers.

\section{Setting \& Sampling-}

The research was conducted in the inpatient setting of the department of Obstetrics (post natal ward) and Paediatrics at a tertiary care teaching hospital in central India from July 2011 to October 2012.

The study was approved by the Institutional Ethics Committee. Orientation about the study topic and protocol was given to staff members; mainly nursing staff taking care of the post natal wards. Confidentiality was assured, the purpose of study and protocol was explained to each mother enrolled. Written informed consent was obtained from all mothers who participated in study. The study subjects were selected through a purposive sampling technique.

\section{Inclusion criteria-}

1. Primipara.

2. Normal vaginal delivery with or without episiotomy or instrumental delivery.

3.Mothers with single \& appropriate weight for gestational age baby.

4. New born babies with normal reflexes.

5. Mothers who are willing to breast feed.

\section{Exclusion criteria-}

1. Newborns with poor neonatal reflexes.

2. Newborns with prematurity, congenital anomalies or any neurological conditions leading to poor sucking reflexes.

3. Mothers with any acute or chronic illness.

4. Mothers with nipple or breast anomalies or attachment difficulties.

5. Mothers on medications affecting Lactation or breast feeding.

\section{Parameters of Assessment (baby)-}

1. Mean of post feed weight gain.

2. Number of urinations per day.

3. Number of stools passed per day.

4. Duration of sleep in hours after breast feeding.

5. Satiety of baby at the end of breast feeding.

The study was conducted over a period of 16 months. 220 subjects were included in the study, in two groups; Group A was the study group of 100 subjects to whom back massage was given and group B, the control group of 120 subjects to whom routine care was provided.

Data collection was completed first from group A and then from group B to ensure smooth and precise recording of data. All subjects of group A had already breastfed their babies at least once within two hours of delivery.

The first back massage was given within two hours of delivery and continued for four times a day at regular intervals for three days. First, the steps of the procedure were explained to the subjects.

After proper exposure and comfortable position, gentle pressure with both thumbs was given on the back, at the lateral sides of spine, in circulatory motion.

Movements were given "to" and "fro" from neck to buttocks and back to neck. This was applied for 15 minutes at each sitting.

Just after massage, fullness of breast was assessed and baby was given to mother for feeding. Pre feed and post feed weight was assessed.

Over the next 3 days, other parameters mentioned above were also assessed.

\section{Results}

There were 100 babies in experimental group (Group A) and 120 babies in control group (Group B). 
Table No-01: Post feed weight gain in Experimental and control group.

\begin{tabular}{|c|c|c|c|c|c|}
\hline $\begin{array}{c}\text { Mean post feed } \\
\text { weight gain (in grams) }\end{array}$ & Mean & SD & $\begin{array}{c}\text { Mean } \\
\text { Difference }\end{array}$ & $\mathrm{df}$ & $\mathrm{t}$ value \\
\hline \multicolumn{6}{|l|}{ First day } \\
\hline Group A & 10.90 & 2.48 & \multirow[t]{2}{*}{4.01} & \multirow[t]{2}{*}{218} & \multirow{2}{*}{$\begin{array}{l}6.89 \\
* * \mathrm{~S}\end{array}$} \\
\hline Group B & 6.89 & 3.02 & & & \\
\hline \multicolumn{6}{|l|}{ Second day } \\
\hline Group A & 24.60 & 3.36 & \multirow[t]{2}{*}{5.32} & \multirow[t]{2}{*}{218} & \multirow{2}{*}{$\begin{array}{l}9.14 \\
* * \mathrm{~S}\end{array}$} \\
\hline Group B & 19.28 & 5.94 & & & \\
\hline \multicolumn{6}{|l|}{ Third Day } \\
\hline Group A & 36.84 & 5.84 & \multirow[t]{2}{*}{6.68} & \multirow[t]{2}{*}{218} & \multirow{2}{*}{$\begin{array}{l}11.47 \\
3 * * \mathrm{~S}\end{array}$} \\
\hline Group B & 30.16 & 7.58 & & & \\
\hline
\end{tabular}

**S: Significant

Table 1 findings reveals that there is higher post feed weight gain in neonates of group A, in all 3 days, as compared to group B. Mean post feed weight gain in group A on first day was (10.9 grams), second day was (24.6 grams) and third day was (36.8 grams), where is group B on first day was (6.89 grams), second day (19.24 grams) and third day (30.16 grams). The computed value is $6.89,9.14$ and 11.47 on first, second and third days respectively. This indicates that back massage is effective in improving milk volume in immediate postpartum mothers.

Table No-2: Frequency of Urination in Experimental and control group.

\begin{tabular}{|c|c|c|c|c|c|c|}
\hline $\begin{array}{c}\text { Number of Urination } \\
\text { per day }\end{array}$ & $\mathrm{N}$ & Mean & $\mathrm{SD}$ & $\begin{array}{c}\text { Mean } \\
\text { Difference }\end{array}$ & df & $\mathrm{t}$ value \\
\hline \multicolumn{7}{|l|}{ First day } \\
\hline Group A & 100 & 3.28 & 0.92 & \multirow[t]{2}{*}{0.36} & \multirow[t]{2}{*}{218} & \multirow[t]{2}{*}{0.68} \\
\hline Group B & 120 & 2.92 & 1.21 & & & \\
\hline \multicolumn{7}{|l|}{ Second day } \\
\hline Group A & 100 & 5.67 & 1.39 & \multirow[t]{2}{*}{0.41} & \multirow[t]{2}{*}{218} & \multirow{2}{*}{$\begin{array}{l}0.77 \\
* * \mathrm{~S}\end{array}$} \\
\hline Group B & 120 & 5.26 & 1.16 & & & \\
\hline \multicolumn{7}{|l|}{ Third Day } \\
\hline Group A & 100 & 7.19 & 1.19 & \multirow[t]{2}{*}{1.11} & \multirow[t]{2}{*}{218} & \multirow{2}{*}{$\begin{array}{c}2.1 \\
* * \mathrm{~S}\end{array}$} \\
\hline Group B & 120 & 6.08 & 1.32 & & & \\
\hline
\end{tabular}

**S: Significant

Table 2 reveals mean number of urinations per day by group A and group B neonates. Mean number of urinations in Group A on first day was (3.28), on second day was (5.67) and on third day was (7.19); where as in Group B on first day was (2.92), on second day was (5.26) and on third day was (6.08).

The computed unpaired t test values on first, second and third day is $0.68,0.77$ and 2.1 respectively. On first and second day $\mathrm{t}$ value did not shows significant statistical difference between Group A and Group B, but on third day it shows significant statistical difference at $<0.05$ level in between both groups.

This indicates that urine output is increased significantly in Group A on third day; this indicates improving lactation in immediate postpartum mothers. 
Table No-3: Frequency of Stool in Experimental and control group

\begin{tabular}{|c|c|c|c|c|c|}
\hline $\begin{array}{l}\text { Number of } \\
\text { stool/day }\end{array}$ & Mean & $\mathrm{SD}$ & $\begin{array}{c}\text { Mean } \\
\text { Difference }\end{array}$ & df & $\mathrm{t}$ value \\
\hline \multicolumn{6}{|l|}{ First day } \\
\hline Group A & 2.68 & 0.72 & \multirow[t]{2}{*}{0.34} & \multirow[t]{2}{*}{218} & \multirow{2}{*}{$\begin{array}{l}0.61 \\
* * * S\end{array}$} \\
\hline Group B & 2.33 & 0.92 & & & \\
\hline \multicolumn{6}{|l|}{ Second day } \\
\hline Group A & 2.43 & 1.28 & \multirow[t]{2}{*}{0.36} & \multirow[t]{2}{*}{218} & \multirow{2}{*}{$\begin{array}{l}0.64 \\
* * \mathrm{~S}\end{array}$} \\
\hline Group B & 2.04 & 1.16 & & & \\
\hline \multicolumn{6}{|l|}{ Third Day } \\
\hline Group A & 3.98 & 1.09 & \multirow[t]{2}{*}{1.36} & \multirow[t]{2}{*}{218} & \multirow{2}{*}{$\begin{array}{l}2.45 \\
* * \mathrm{~S}\end{array}$} \\
\hline Group B & 2.62 & 1.21 & & & \\
\hline
\end{tabular}

**S: Significant

Table 3 reveals mean number of stools passed per day by neonate in Group A and Group B. Mean number of stool in Group A on first day was (2.67), on second day (2.43) and on third day (3.98), where as in group B on first day was (2.33), on second day (2.07) and on third day it was (2.62). The computed unpaired t test value on first, second and third day is $0.61,0.64$ and 2.45 respectively. On first and second day $t$ value did not show any significant statistical difference between Group A and Group B, but on third day it shows significant statistical difference at $<0.05$ level in between both groups. This indicate back massage is effective in improving lactation in immediate postpartum mothers as seen by mean difference in stool frequency on first and second day and significant statistical difference on third day.

Table No-4: Duration of sleep in Experimental and control group

\begin{tabular}{|c|c|c|c|c|}
\hline $\begin{array}{l}\text { Duration of sleep } \\
\text { after breastfeeding }\end{array}$ & Group A & Group B & $\mathrm{df}$ & Chi-square value \\
\hline First day & & & & \\
\hline$<1 / 2$ hour & 04 & 07 & \multirow{4}{*}{3} & \multirow{4}{*}{$\begin{array}{l}20.190 \\
* * * \mathrm{~S}\end{array}$} \\
\hline $1 / 2-1$ hour & 09 & 31 & & \\
\hline 1-2 hour & 58 & 38 & & \\
\hline$>2$ hour & 29 & 44 & & \\
\hline \multicolumn{5}{|l|}{ Second Day } \\
\hline$<1 / 2$ hour & - & - & \multirow{4}{*}{2} & \multirow{4}{*}{$\begin{array}{l}22.078 \\
* * * \mathrm{~S}\end{array}$} \\
\hline $1 / 2-1$ hour & - & 18 & & \\
\hline $1-2$ hour & 28 & 45 & & \\
\hline$>2$ hour & 72 & 57 & & \\
\hline \multicolumn{5}{|l|}{ Third day } \\
\hline$<1 / 2$ hour & - & - & \multirow{4}{*}{2} & \multirow{4}{*}{$\begin{array}{l}31.709 \\
* * * \mathrm{~S}\end{array}$} \\
\hline $1 / 2-1$ hour & - & 04 & & \\
\hline $1-2$ hour & 13 & 54 & & \\
\hline$>2$ hour & 87 & 62 & & \\
\hline
\end{tabular}

**S: Significant

Table 4 reveals that majority of neonates in Group A (58\%) slept for 1-2 hours on first day after each feed where as in Group B most of neonate (36\%) slept for $>2$ hours, on second day $72 \%$ from Group A slept for $>2$ hours while $47 \%$ from group B slept for $>2$ hours. On third day majority of neonates (87\%) from Group A slept for $>2$ hours where as $51.6 \%$ neonates from Group B slept for $>2$ hours. Chi-square value of all subsequent three days were 20.190, 22.078 and 31.709 which is found statistically significant at $\mathrm{P}<0.05$ level on all 3 days. 
Table No-5: Feeding Satisfaction in Experimental and control group

\begin{tabular}{|c|c|c|c|c|}
\hline $\begin{array}{l}\text { Satiety of baby at the end of } \\
\text { feeding session }\end{array}$ & Group A & Group B & df & $\begin{array}{l}\text { Chi-square } \\
\text { value }\end{array}$ \\
\hline First day & & & & \\
\hline Cries & 0 & 26 & \multirow{4}{*}{3} & \multirow{4}{*}{$\begin{array}{c}53.947 \\
* * * \mathrm{~S}\end{array}$} \\
\hline Fusses & 8 & 43 & & \\
\hline Unsatisfied but sleeps & 57 & 39 & & \\
\hline Satisfied andsleeps easily & 39 & 12 & & \\
\hline \multicolumn{5}{|l|}{ Second day } \\
\hline Cries & 0 & 0 & \multirow{4}{*}{2} & \multirow{4}{*}{$\begin{array}{l}24.379 \\
* * * \mathrm{~S}\end{array}$} \\
\hline Fusses & 2 & 27 & & \\
\hline Unsatisfied but sleeps & 29 & 41 & & \\
\hline Satisfied andsleeps easily & 69 & 52 & & \\
\hline \multicolumn{5}{|l|}{ Third day } \\
\hline Cries & 0 & 0 & \multirow{4}{*}{2} & \multirow{4}{*}{$\begin{array}{l}33.513 \\
* * * \mathrm{~S}\end{array}$} \\
\hline Fusses & 0 & 13 & & \\
\hline Unsatisfied but sleeps & 7 & 39 & & \\
\hline Satisfied andsleeps easily & 93 & 68 & & \\
\hline
\end{tabular}

**S: Significant

Table 5 reveals that $35 \%$ babies in Group A and only 10\% babies from Group B were satisfied after breastfeeding on first day, where as $69 \%$ from Group A and $43.3 \%$ babies from Group B were satisfied after breastfeeding on day 2. On third day 93\% from Group A and 56.6\% from Group B were satisfied from breastfeeding.

Chi-square value of all three days were 53.947, 24.379 and 33.513 which was found statistically significant at $\mathrm{P}<0.05$ level on all 3 days.

\section{Discussion}

Although it is well known that when properly initiated and practiced, the amount of breast milk should beb sufficient even for twin babies, it is not infrequent to come across immediate post natal mothers and their caretakers extremely concerned regarding the adequacy of the quantity of breast milk for the baby.

This is more so with primiparous mothers. This concern prompts the use of top milk feeding, which in turn would lead to decreased sucking.

This coupled with the mother's anxiety, starts a vicious cycle and the amount of breast milk may actually start decreasing. A multipronged approach including proper timing of initiation, adequate education of the mother regarding breast feeding practices and psychological support can help a long way.

The present study was an attempt at identifying the effectiveness of a simple, easily adaptable, and public health system friendly method - back massage on improving lactation.

Massage is a relaxation technique, and reduces stress[11] which probably is responsible for increase in milk output. It was found in the present study that mean post feed weight gain is higher in study group, which indicates increase lactation in mothers after back massage. 
Other studies have shown similar effects, though the site of massage/acupressure was different $[12,13]$. The mean number per day of urination and stools passed by the babies were higher in study group. Increased lactogenesis in experimental group may be responsible for more frequent urine and stool output. Similar results were in other studies [14].

Similarly, the duration of sleep and satisfaction after feeding was more in study group, supporting the hypothesis that back massage improves lactation.

Compared to other non pharmacologic measures used for stimulating lactation like acupuncture and infrared radiation[15,16], back massage is far simpler, practical and will not pose strain on the public health system.

\section{Conclusions}

The study shows that

1. Post feed weight gain is statistically significantly higher in study group, which indicates that back massage has a positive effect on lactation.

2. Parameters like number of urinations and stools passed per day by the babies were higher in study group, which again indicate improved lactation in study group.

3. Mothers of study group were more satisfied with satiety and sleep of their babies; these parameters were also statistically significant, which also indicates positive impact on lactation.

Back massage was effective in improving the lactation in all parameters assessed. This can be recommended for all breastfeeding mothers, especially for those facing the problems in initiating and sustaining breast feeding.

Importantly, this is a simple method which can be implemented using the existing healthcare personnel, without straining resources.

Acknowledgement: The authors want to thanks all the subjects, their young neonates for participating in study.

\section{Funding: Nil \\ Conflict of interest: None \\ Permission from IRB: Yes}

\section{References}

1. Blaymore JA, Oliver T, Ferguson A, et al. Human milk reduces outpatient upper respiratory symptoms in premature infants during their first year of life. J Perinatol $2002 ; 22: 354-9$.
2. Ruben G, Rafael PE. Stress during Labour \& Delivery is Associated with Delay onset of Lactation Among Urban Guatemalan Women. J. Nutr.2002; 132(10):3055- 60.

3. Ueda T, Yokoyama Y, Irahara M, Aono T. Influence of Psychological Stress on Suckling Inducad Pulsatile Oxytocin Reasese. Obslet Gynecol.1994; 84(2):259-62.

4. Ruvalcaba HA. Stress Induced Cessation of Lactation. West J Med.1987; 146:228-30.

5. Mathur GP, Chitranshi S, Mathur S, Singh SB, Bhalla M. Lactation Failure. Indian Pediatr.1992; 29(12):1541-44

6. Kathryn G. Dewey. Maternal and Fetal Stress are Associated with Impaired Lactogenesis in Human. J. Nutr.2001; 131(11):3012- 15.

7. Kristine C. Cowley. Psychogenic And Pharmacologic Induction of the Letdown Reflex can facilitate Breastfeeding by tetraplegic women: A report of 3 cases. Arch Phys Med Rehabil.2005; 86:1261-64.

8. K. Sakha, A.G.G. Behbahan. The onset Time of Lactation after Delivery. Medical Journal of The Islamic Republic of Iran. 2005; 19(2):135-39.

9. National Family Health. Survey (NFHS-3). 2005-06. Volume I. International Institute for Population Sciences. Deonar, Mumbai 400 088. Ministry of Health and family walfare. Available online at: www.measuredhs.com/pubs/pdf/ FRIN D3/FRIND3VOL2.pdf.

10. Wang HC, Jim A, Han Y, et al. Multi central Randomized Controlled Studies on Accupuncture at Shaoze (SI 1) for Treatment of postpartum Hypolactation. Zhongguo Zhen Jiu.2007;b27(2):85-88.

11. O'Connor ME, Schmidt W, Pankhurst CC, Olness KN. Relaxation Trainning and Breast Milk Secretary IgA. Arch Pediatr Adolesc Med. 1998;b152(11):1065-70.

12. Lu P, Qui J, Yao F, Zheng JJ. Effect of accupoint Twina on Lactation amount for Parturient. Zhongguo Zhen Jiu 2010; 30(9):731-33.

13. Zhou HY,Li L, Dan DL, et al. Clinical observation on Treatment of Post Cesarean Hypogalactia by auricular points sticking. Chin J Integr Med. 15 (2):2009; 117-20.

14. Nommesen-Rivers LA, Heinig MJ, Cohen RJ, Dewey KG. Newborn Wet And Soiled Diapper count and Timing of Onset of Lactation as indicator of Breastfeeding Inadequacy. J Hun Lact.2008 ; 24(1):27-33. 
15. He JQ, Chen BY, Huang $\mathrm{T}$, et al. Randomized Controlled multicertral Study on Acupuncture at Tan zhong (CV 17) for treatment of post partum Hypolactation. Zhongguo Zhen Jiu. 2008; 28(5):317-20.
16. Ogita S, Imanaka M, Matsua S,et al. Effect of Farinfrared radiation on Lactation. Ann Physiol Anthropol. 1990; 9(2):83-91.

\section{How to cite this Article?}

Patel U, Gedam DS, Verma M. Effect of back Massage on Lactation among Postnatal Mothers. Int J Med Res Rev 2013; 1(1):05-11.doi: 10.17511/ijmrr.2013.i01.02. 